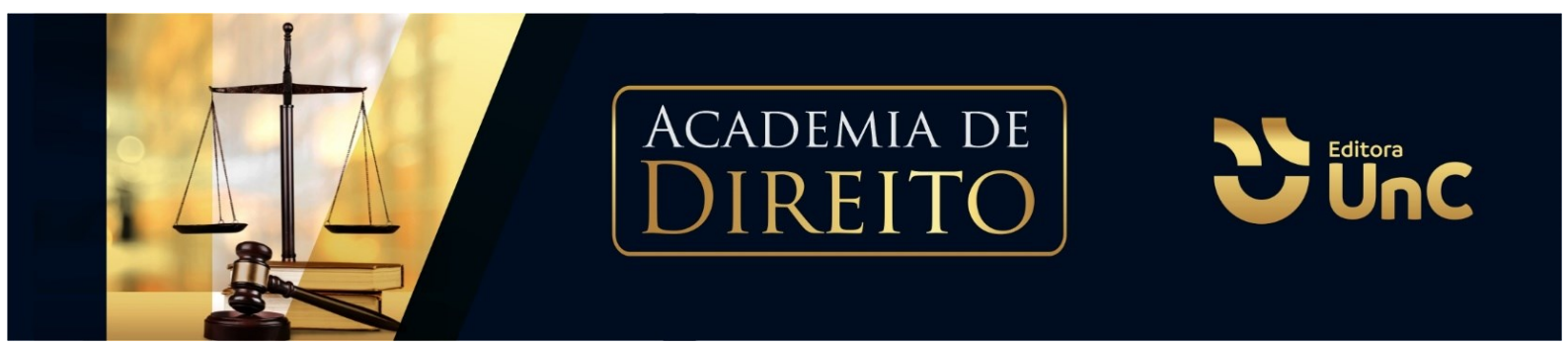

\title{
O MONITORAMENTO ELETRÔNICO COMO FORMA DE CONTROLE DAS MEDIDAS PROTETIVAS DE URGÊNCIA
}

\section{ELETRONIC MONITORING AS A FORM OF CONTROL OF PROTECTIVE EMERGENCY MEASURES}

\section{RESUMO}

Este artigo tem como objetivo analisar a aplicabilidade da monitoração eletrônica nos casos de violência doméstica. Para tanto, serão abordados aspectos relacionados à Lei 11.340 de 2006, que se apresenta como instrumento legal sobre a violência doméstica contra a mulher, destacando-se o avanço da proteção dos direitos fundamentais e das necessidades características das mulheres, durante o caminho até chegar na priorização da proteção. Posteriormente, estudar-se-á a monitoração eletrônica como instrumento do direito penal brasileiro, com ênfase nos avanços tecnológicos trazidos pela evolução da sociedade, sendo consideradas as ferramentas de auxílio no combate ao avanço da criminalidade e as divergências doutrinárias acerca da possibilidade de estar o monitoramento eletrônico, enquanto instrumento de controle penal estatal, ferindo direitos fundamentais e o princípio da dignidade da pessoa humana, haja vista a carência de regulamentação específica pela legislação brasileira. O objetivo principal é, portanto, analisar a possibilidade de utilização do monitoramento eletrônico como mecanismo no cumprimento das medidas de proteção previstas na Lei Maria da Penha, pelo que é justamente esse o problema enfrentado na presente pesquisa: é possível aplicar o monitoramento eletrônico no âmbito da Lei Maria da Penha? Para buscar a resposta, cuja hipótese se dá no sentido positivo, é realizada revisão bibliográfica e análise jurisprudencial como metodologia empregada, concluindo-se nesse sentido pela confirmação da hipótese, pois desde que respeitadas as premissas que fundacionam o processo penal, entende-se como possível o uso de tal medida cautelar como forma de assegurar as medidas protetivas de urgência.

Palavras-Chave: Violência doméstica. Lei Maria da Penha. Monitoração eletrônica.

\footnotetext{
${ }^{1}$ Acadêmica do curso de Direito da Universidade do Contestado (UnC). Campus Canoinhas. Santa Catarina. Brasil. E-mail: valleleticia003@gmail.com

${ }^{2}$ Mestre em Direito pelo Centro Universitário Internacional (UNINTER). Docente da Universidade do Contestado. Santa Catarina. Brasil. E-mail: paulosilasfilho@hotmail.com
} 


\begin{abstract}
This article aims to analyze the applicability of electronic monitoring in cases of domestic violence. To this end, aspects related to Law 11.340 of 2006, which is presented as a legal instrument on domestic violence against women, will be discussed, highlighting the advancement of the protection of fundamental rights and the characteristic needs of women, along the way until reaching the prioritizing protection. Subsequently, electronic monitoring will be studied as an instrument of Brazilian criminal law, with an emphasis on technological advances brought about by the evolution of society, considering the tools to assist in the fight against the advance of crime and the doctrinal divergences about the possibility of being electronic monitoring, as an instrument of state penal control, violating fundamental rights and the principle of human dignity, given the lack of specific regulation under Brazilian law. The main objective is, therefore, to analyze the possibility of using electronic monitoring as a mechanism to comply with the protection measures provided for in the Maria da Penha Law, which is precisely the problem faced in the present research: it is possible to apply electronic monitoring in the context of the Maria da Penha Law? In order to seek the answer, whose hypothesis is in the positive sense, a bibliographic review and jurisprudential analysis is performed as the methodology used, concluding in this sense by confirming the hypothesis, since as long as the premises underlying the criminal procedure are respected, it is understood as the use of such a precautionary measure is possible as a way to ensure emergency protective measures.
\end{abstract}

Keywords: Domestic violence. Maria da Penha Law. Electronic monitoring.

\title{
1 INTRODUÇÃO
}

As relações humanas sofrem a influência das mudanças sociais, repercutindo de forma substancial no regramento jurídico, o que implica na evolução das normas jurídicas garantidoras dos direitos e garantias das pessoas.

Todas as situações específicas necessitam ser tuteladas, garantindo os direitos em todos os aspectos. Nesse contexto, destaca-se o avanço da proteção dos direitos fundamentais e das necessidades características das mulheres, fenômenos que passou por um longo caminho até chegar na priorização da proteção nesse âmbito, numa postura contra o cultivo de valores que incentivam a violência, fruto da desigualdade sociocultural que fomentou a discriminação feminina.

Após longo período de subjugação da mulher, que obtinha um papel de inferioridade na sociedade, iniciou-se um processo de mudanças, voltado para a proteção, com vistas a coibir a violência doméstica contra a mulher, uma vez que por longo período seus direitos eram mínimos, com liberdade restrita, concentrando-se o 
eixo da família na figura patriarcal, restando à elas uma posição de submissão, sem liberdade de expressão.

Nesse contexto, apresentam-se as mudanças legislativas, notadamente aquelas trazidas pela Lei 11.340 de 2006, a Lei Maria da Penha, que se apresenta como instrumento direcionado à superação das práticas relacionadas à violência doméstica. Aliada a outras previsões legais, especialmente as constitucionais, simboliza a alteração de paradigma quanto à não-aceitação da violência contra a mulher.

Muitos foram os benefícios trazidos pela Lei $\mathrm{n}^{\circ} 11.340 / 06$, que trata expressamente das modalidades de violência doméstica e familiar e prevê medidas de proteção e assistência à mulher, inovando no que concerne ao conceito de medida protetiva já existente no ordenamento jurídico brasileiro.

Entretanto, a efetividade das medidas depende de uma fiscalização concreta, pois sem ela as medidas protetivas de urgência não garantem a proteção integral da vida da mulher em situação de violência.

Nesse contexto, destacam-se os diversos métodos utilizados para garantir a efetividade das medidas, despontando o monitoramento eletrônico como um meio de atingir o objetivo da Lei, a saber, o de proteger a vítima. Entretanto, em razão da ausência de previsão legal, faz-se necessário analisar os aspectos relacionados à aplicabilidade da monitoração eletrônica nos casos de violência doméstica.

Assim, o problema da pesquisa a ser enfrentado é "a medida cautelar de monitoramento eletrônico pode ser utilizada como forma de assegurar às medidas protetivas de urgência"? Objetiva-se com esse estudo analisar se ao se aplicar institutos processuais de leis diversas (Código de Processo Penal e Lei Maria da Penha) estaria se incorrendo em indevido sincretismo ou se há possibilidade permissiva nesse sentido. O método empregado para tanto é a revisão bibliográfica sobre o tema, bem como a análise jurisprudencial sobre casos que já enfrentaram o tema, pelo que a divisão tópica que aqui segue percorre justamente a noção da construção e consolidação dos direitos das mulheres, as medidas protetivas de urgência, as medidas cautelares processuais e a discussão sobre o tema central que norteia a presente pesquisa. 


\section{A LEI MARIA DA PENHA E A QUESTÃO DAS MEDIDAS IMPOSTAS AO AGRESSOR}

A violência doméstica é efeito de um contexto social marcado por uma cultura de banalização da figura feminina. O problema histórico da desigualdade de gênero, vem aos poucos sendo minimizado pela implantação de instrumentos direcionados à superação de tais práticas.

Nesse contexto a Lei 11.340 de 2006, aliada a outras previsões legais, especialmente as constitucionais, simboliza a alteração de paradigma quanto à nãoaceitação da violência contra a mulher e surge como instrumento legal para combater a violência doméstica contra a mulher, buscando tornar mais efetiva a superação do paradigma da desigualdade de gênero.

As diversas políticas públicas, dentre as quais se destaca a Lei Maria da Penha, são direcionadas à luta contra uma sociedade desigual e a promoção dos direitos fundamentais femininos para que a dignidade humana atinja o mesmo patamar entre homens e mulheres, consagrando a noção de igualdade prevista na Constituição Federal.

As lutas pelo reconhecimento de direitos no país, somada a uma histórica luta internacional, por meio convenções e tratados para erradicação da discriminação e a violência, levou o Brasil a criar o seu próprio meio de punir e erradicar a violência contra a mulher (VOLLET; TAPOROSKY FILHO, 2019).

A Lei 11.340 de 2006, surge da necessidade de uma postura positiva do Estado na construção de uma sociedade igualitária, e apresenta-se como instrumento legal para combater a violência doméstica contra a mulher, conferindo efetividade aos preceitos constitucionais e criando mecanismos para coibir a violência doméstica e familiar contra a mulher, e pode ser considerada uma resposta aos movimentos internacionais em defesa dos direitos femininos, surgindo em um contexto de grande movimentação internacional de reconhecimento da violência contra a mulher como uma violação aos direitos humanos, como importante conquista na luta contra a realidade cultural e histórica de desigualdade de gênero. Nesse sentido, pode-se apontar o feminismo como importante movimento nesse sentido, uma vez que a partir desse se tem a "luta pela igualdade de gênero, para que possa viver em harmonia 
com ele, estabelecendo uma cultura de paz e uma sociedade de consciência crítica, a fim de que direitos e deveres sejam preservados" (LíDICE, 2018, p. 173).

A desigualdade histórica das relações de poder entre homens e mulheres ensejou em necessárias intervenções internacionais que determinaram o posicionamento preventivo e punitivo dos Estados no sentido de eliminar a violência. No Brasil, a Lei 11.340/2006, chamada de Lei Maria da Penha, trata especificamente da violência baseada no gênero (BRASIL, 2006).

\begin{abstract}
A Lei Maria da Penha não trata de toda a violência contra a mulher, mas somente daquela baseada no gênero (art. 5o, caput). Tal delimitação decorre da redação contida no dispositivo antes mencionado, o qual estabelece que, 'para os efeitos desta Lei [Lei Maria da Penha], configura violência doméstica e familiar contra a mulher qualquer ação ou omissão baseada no gênero' (BIANCHINI, 2016, p.31).
\end{abstract}

Os impactos da trazidos pela Lei $n^{\circ} 11.340 / 2006$ implicam em relevantes repercussões sociais para as mulheres, conferindo efetividade aos preceitos constitucionais e criando mecanismos para coibir a violência doméstica e familiar.

Acerca do objetivo da Lei e os conceitos legais, destacam as disposições do preâmbulo, que prevê o objetivo específico de criar mecanismos para coibir a violência doméstica e familiar, estabelecendo ações de assistência às vítimas e adoção de medidas repressoras contra o agressor, com a previsão das formas de violência doméstica, servindo como base para serem identificadas as situações tuteladas pela Lei e em resposta serem estabelecidas ações de assistência às vítimas com a adoção de medidas repressoras contra o agressor (TAPOROSKY FILHO; VOLLET, 2019).

$\mathrm{O}$ art. $5^{\circ}$ da Lei $11.340 / 2006^{3}$ define violência doméstica e familiar contra a mulher e os âmbitos em que tal violência ocorreria, em uma conceituação ampla,

\footnotetext{
3"Art. $5^{\circ}$ Para os efeitos desta Lei, configura violência doméstica e familiar contra a mulher qualquer ação ou omissão baseada no gênero que lhe cause morte, lesão, sofrimento físico, sexual ou psicológico e dano moral ou patrimonial:

I - no âmbito da unidade doméstica, compreendida como o espaço de convívio permanente de pessoas, com ou sem vínculo familiar, inclusive as esporadicamente agregadas;

II - no âmbito da família, compreendida como a comunidade formada por indivíduos que são ou se consideram aparentados, unidos por laços naturais, por afinidade ou por vontade expressa;

III - em qualquer relação íntima de afeto, na qual o agressor conviva ou tenha convivido com a ofendida, independentemente de coabitação.

Parágrafo único. As relações pessoais enunciadas neste artigo independem de orientação sexual" (BRASIL, 2006).
} 
estabelecendo, no parágrafo único que as relações enunciadas independem de orientação sexual (BRASIL,2006).

Outra modificação importante trazida pela Lei analisada encontra-se no artigo $7^{04}$, que traz expressamente as modalidades de violência doméstica e familiar que, além de física, pode ser psicológica, sexual, patrimonial e moral, sendo estas as mais comumente praticadas no âmbito familiar e doméstico, e prevê medidas de proteção e assistência à mulher, inovando no que concerne ao conceito de medida protetiva já existente no ordenamento jurídico brasileiro (BRASIL, 2006).

A violência física, uma das formas de violência que a vítima poderá sofrer, é a primeira elencada e a mais facilmente aferível, pois deixa vestígios, caracterizada pelo uso da força, com o objetivo agredir a vítima, ofendendo sua integridade física, deixando ou não marcas aparentes (FERNANDES, 2015).

A próxima elencada no rol do referido artigo é a violência psicológica, tipo de violência que deixa marcas invisíveis e podem comprometer o bem estar emocional da vítima, causando danos irreparáveis, caracterizada pela agressão emocional (FERNANDES, 2015).

Para a proteção integral da vítima, o conceito de violência psicológica pode ser considerado como lesão corporal à saúde da vítima e consideradas as disposições do artigo 129 do Código Penal, no sentido de que as alterações de ordem psíquica estão incluídas nas espécies de lesão contra a pessoa (BORGES, 2020). Essa forma de compreensão mais abrangente do tipo penal que traz a figura da lesão corporal é

\footnotetext{
4 "Art. $7^{\circ}$ São formas de violência doméstica e familiar contra a mulher, entre outras:

I - a violência física, entendida como qualquer conduta que ofenda sua integridade ou saúde corporal; II - a violência psicológica, entendida como qualquer conduta que the cause dano emocional e diminuição da autoestima ou que lhe prejudique e perturbe o pleno desenvolvimento ou que vise degradar ou controlar suas ações, comportamentos, crenças e decisões, mediante ameaça, constrangimento, humilhação, manipulação, isolamento, vigilância constante, perseguição contumaz, insulto, chantagem, violação de sua intimidade, ridicularização, exploração e limitação do direito de ir e vir ou qualquer outro meio que lhe cause prejuízo à saúde psicológica e à autodeterminação;

III - a violência sexual, entendida como qualquer conduta que a constranja a presenciar, a manter ou a participar de relação sexual não desejada, mediante intimidação, ameaça, coação ou uso da força; que a induza a comercializar ou a utilizar, de qualquer modo, a sua sexualidade, que a impeça de usar qualquer método contraceptivo ou que a force ao matrimônio, à gravidez, ao aborto ou à prostituição, mediante coação, chantagem, suborno ou manipulação; ou que limite ou anule o exercício de seus direitos sexuais e reprodutivos;

IV - a violência patrimonial, entendida como qualquer conduta que configure retenção, subtração, destruição parcial ou total de seus objetos, instrumentos de trabalho, documentos pessoais, bens, valores e direitos ou recursos econômicos, incluindo os destinados a satisfazer suas necessidades; $\mathrm{V}$ - a violência moral, entendida como qualquer conduta que configure calúnia, difamação ou injúria" (BRASIL, 2006).
} 
ainda bastante controvertida no âmbito jurídico, uma vez que diz respeito a certa forma de interpretação extensiva da norma penal. Se é ou não possível considerar a violência psicológica como a figura típica presente no artigo 129 do Código Penal, tem-se aí questão problemática que clama a atenção da comunidade jurídica, fazendo-se necessário o estudo da doutrina sobre tal ponto, uma vez que já há vozes apontando para a possibilidade nesse sentido.

A terceira forma de violência trazida pelo art. $7^{\circ}$ da Lei $11.340 / 06$ é a sexual, caracterizada por uma conduta que provoca na vítima um constrangimento, limitando a autodeterminação sexual da mesma, normalmente ocorre acompanhada de violência física ou violência psicológica (FERNANDES, 2015).

Outra forma de violência elencada na Lei é a patrimonial, acontece quando o ato de violência implica em retenção, subtração ou destruição de patrimônio da vítima. Muitas vezes o agressor usa os bens da vítima como moeda de troca (FERNANDES, 2015).

A última forma trazida pelo artigo $7^{\circ}$ da Lei $11.340 / 06$, é a violência moral. Tal forma remete a condutas que configurem calúnia, injúria ou difamação, conceitos já existentes no ordenamento jurídico brasileiro e com previsão expressa no Código Penal (FERNANDES, 2015).

A Lei Maria da Penha atua como instrumento favorável e direcionado ao afastamento das práticas de violência doméstica e familiar, dando o equilíbrio para a dignidade e a igualdade da mulher perante a sociedade. Nesse sentido:

\begin{abstract}
O novo regramento legal parte do reconhecimento de que há todo um conjunto de poder simbólico, interiorizado por homens e mulheres desde a infância, que coloca a mulher em uma postura de dependência e acaba por fragilizá-la na relação de gênero, especialmente no âmbito doméstico, potencializando sua vitimização e criando óbices à alteração deste status, pela dificuldade psicológica de sua denúncia e pela tendência de minimização da gravidade da violência pelas instâncias formais e informais de controle social. Infelizmente, não é raro ouvir-se a expressão que "agressão de marido contra mulher não é "violência contra a mulher" mas violência contra a sua mulher", argumento estapafúrdio fundado numa perspectiva coisificante da mulher e utilizada para justificar a desnecessidade de interferência do Estado para quebrar este ciclo de violência que se repete diariamente em milhares de lares (ÁVILA, 2007, p. 02).
\end{abstract}

A Lei Maria da Penha, em sua base fundante, além do viés repressivo, busca efetivamente proteger a vítima, reeducar o agressor e romper o ciclo da violência. $O$ 
processo protetivo é composto pelas medidas cautelares que obrigam o agressor (FERNANDES, 2015).

Para a efetividade dos processos protetivo e criminal de violência doméstica, o aplicador do Direito deve apropriar-se de conceitos metajurídicos, como forma de compreender os motivos que levam a vítima a não processar o agressor. Sem essa abordagem, a tendência é de que todos os inquéritos sejam arquivados ou os réus absolvidos, ante o repetitivo comportamento da vítima - ainda que esteja em grave situação de risco - de inocentar o agressor (FERNANDES, 2015, p.124).

As medidas de proibição de aproximação, proibição de contato e proibição de frequentar determinados lugares estão diretamente relacionadas a efetividade da proteção. A fiscalização das mencionadas medidas pode ser exercida pela vítima, sendo possível também, a utilização de outros métodos para garantir o cumprimento (BIANCHINI, 2018).

São de extrema importância as medidas de proteção destinadas à mulher e aos dependentes, pois se prestam a compensar a desigualdade histórica entre homens e mulheres, buscando minimizar a vulnerabilidade da mulher.

\begin{abstract}
A Lei Maria da Penha inovou na medida em que modificou as funções das autoridades públicas responsáveis pela persecução penal, que ressurgem como agentes transformadores. Trata-se de uma importante providencia, pois a Policia Civil e o Ministério Público, amparados pelo aparato do Estado, tem melhores condições de atender, orientar e encaminhar as vítimas (FERNANDES, 2015, p. 236).
\end{abstract}

Atualmente, são implantadas diferentes ações e serviços de atendimento à mulher em situação de violência, por iniciativa da assistência social, da justiça, da saúde, e outras. Tais medidas visam ampliar e melhorar a qualidade do atendimento; identificando e encaminhando as mulheres vítimas de violência ao acompanhamento necessário (FERNANDES, 2015).

O Estado assegura, em todas as fases do processo, o direito a proteção judiciária (SOUZA, 2008). Acerca do tratamento dado ao processo na Lei Maria da Penha destaca-se:

Nesta Lei, a sua atuação está vinculada principalmente à defesa da ordem jurídica e dos interesses sociais e individuais indisponíveis. No que diz respeito aos crimes cuja competência consta desta Lei, o Ministério Público agirá na sua principal função, que é a de proteção da ordem jurídica quando 
afetada na esfera criminal, agindo como parte, ao passo que, em relação aos demais atos que reclamam a sua intervenção, estarão agindo no resguardo dos interesses sociais e individuais indisponíveis, principalmente da dignidade da vítima de violência, na maioria das vezes como fiscal da lei 'custus legis' (SOUZA, 2008, p.155).

No Brasil, além de serem observadas as normas gerais e específicas previstas no ordenamento jurídico, também devem ser seguidas as disposições previstas nos acordos internacionais que apresentam recomendações sobre a erradicação de qualquer forma de discriminação e violência contra as mulheres, e que visam assegurar de forma direta ou indireta os direitos humanos das mulheres bem como a eliminação de todas as formas de discriminação e violência baseadas no gênero, dos quais o país é signatário (BIANCHINI, 2018).

Mesmo com a criação de várias medidas implementadas, na busca do enfrentamento da questão da violência de gênero, e as políticas públicas e sociais criadas a um nível internacional, envolvendo desde os países menores aos maiores, a desigualdade de gênero ainda é um problema mundial. Constantemente são implementadas políticas públicas a nível municipal, estadual e federal, no enfrentamento da violência contra as mulheres, que permanece sendo um problema a ser encarado com absoluta prioridade, ante o impacto na sociedade (FERNANDES, 2015).

A intervenção da equipe multidisciplinar, composta por outras áreas, como assistência social, psicologia, etc, permite agregar um conhecimento extrajurídico ao processo, de modo a avaliar de forma mais concreta, a vítima e o agressor. É nesse sentido que é sempre bom lembra que "o enfrentamento dos casos de violência contra mulheres, independentemente do contexto socioeconômico, deve extrapolar a dimensão penal e fomentar políticas públicas de fortalecimento das mulheres" (STUKER, 2020, p. 172).

As maneiras de fiscalizar o cumprimento das medidas protetivas são uma questão prática muito relevante a ser analisada. É indispensável saber se o agressor está cumprindo com a exigência de manter o limite mínimo de distância da vítima, ou deixando de frequentar lugares determinados em decisão judicial. Deste modo, ao se analisar a instrumentalização das medidas protetivas de urgência, possibilita-se "questionar vários pontos no que tange a sua aplicabilidade, a ação penal competente e os objetivos a serem alcançados" (FERRAZ; SANTOS, 2020, p. 125). 
Não há previsão legal de métodos específicos para o monitoramento das medidas de afastamento. Entretanto, a monitoração eletrônica, prevista enquanto medida cautelar diversa da prisão no artigo 319, IX do Código de Processo Penal, (BRASIL, 2011), apresenta-se como uma possibilidade para a fiscalização e garantia da decisão judicial de afastamento.

\section{A MONITORAÇÃO ELETRÔNICA COMO INSTRUMENTO PROCESSUAL PENAL}

As dificuldades no sistema penitenciário levam a busca constante por alternativas à prisão, especialmente no âmbito da criminalidade de menor potencial ofensivo, e aliado ao avanço tecnológico desponta a possibilidade de introduzir determinados mecanismos de controle eletrônico no âmbito penal e penitenciário. Nesse contexto está o monitoramento eletrônico.

A monitoração eletrônica de presos desponta sob uma ótica de adaptação da realidade do direito penal aos avanços tecnológicos trazidos pela evolução da sociedade. Muito embora o uso das tornozeleiras eletrônicas apresente-se como medida alternativa para o monitoramento dos presos, recebe críticas por parte da doutrina, que questiona a constitucionalidade da medida. Assim, em que pese todas as críticas cabíveis à medida, principalmente quando sob o enfoque criminológico, tem-se que enquanto forma alternativa ao cárcere, trata-se de medida que pode contribuir para fenômenos tantos como o da necessária redução do superencarceramento, repercutindo assim para com a atual crise do sistema carcerário brasileiro (BIANCHINI, 2018).

Considerando a problemática envolvendo os presídios no Brasil, o monitoramento eletrônico apresenta-se como uma medida alternativa ao desafogamento dos estabelecimentos prisionais (SOUZA, 2008).

Luciano de Oliveira Souza Junior (2008, p. 33) descreve o monitoramento eletrônico como instrumento de controle penal estatal, modalidade de prisão virtual, em que o apenado passa a utilizar um aparelho que permite seu rastreamento via satélite, complementando: 
Trata-se do Sistema de Acompanhamento de Custódia 24 horas - SAC 24, que funciona através de rádio frequência e informações criptografadas fornecedoras de dados sobre o posicionamento do apenado. Tais informações são enviadas a um servidor e disponibilizadas a um programa próprio, com dados acessíveis por um terminal conectado à rede da internet. O controle é realizado através do uso de bracelete, pulseira ou tornozeleira de aproximadamente $75 \mathrm{~g}$ (setenta e cinco gramas), que é equipada com sensores antifraudes e rupturas, funcionando como um transmissor com bateria de vida útil de 12 meses, recarregável.

O monitoramento eletrônico foi introduzido no ordenamento jurídico brasileiro, dizendo-se aqui enquanto medida cautelar diversa da prisão preventiva, no sentido de possibilitar ao juiz o uso dessa medida em caso de necessidade cautelar processual. Nesse sentido, "as medidas cautelares de natureza processual penal buscam garantir o normal desenvolvimento do processo e, como consequência, a eficaz aplicação do poder de punir. São medidas destinadas à tutela do processo" (LOPES JR., 2013, p. 25). É nesse sentido, portanto, que merece observância o instituto das tornozeleiras eletrônicas enquanto medida processual.

Fica ainda o questionamento quanto à possibilidade de estar o monitoramento eletrônico, enquanto instrumento de controle penal estatal, ferindo direitos fundamentais e o princípio da dignidade da pessoa humana.

A Constituição Federal do Brasil é a base principal dos princípios básicos dos homens e mulheres, e é onde estão consolidadas suas garantias e direitos, destacando-se na Constituição de 1988, a dignidade da pessoa, que surge como núcleo informador do ordenamento jurídico brasileiro, princípio sob o qual se ergue o Estado brasileiro, apresentando-se como valor absoluto de cada ser humano, segundo Liberati (2010, p. 18), "A garantia e a proteção desses direitos deverão ser exercidos, assegurando aos seus beneficiários, quer pela lei ou por qualquer outro meio, todas as facilidades para o desenvolvimento físico, moral, mental, espiritual e social, com dignidade e liberdade".

Nesse contexto, é possível constatar a grande ênfase dada à proteção, que nos moldes da Constituição Federal Brasileira é um dos fundamentos do princípio basilar do ordenamento jurídico brasileiro, o princípio da dignidade da pessoa humana.

Os direitos e garantias fundamentais, reconhecidos expressamente ou não no texto constitucional, guardam seu alicerce no princípio fundamental da dignidade da pessoa humana, que garante que os valores inerentes à condição humana sejam resguardados (LIBERATI, 2010). 
No tocante aos direitos fundamentais, os direitos da personalidade são irrenunciáveis, assim como o princípio da dignidade da pessoa humana, uma vez que a dignidade é atributo do homem, e todos os seres humanos são iguais, principalmente quando falamos de direitos da pessoa, como o direito à vida (LIBERATI, 2010).

Isso envolve o respeito e a proteção dos direitos individuais dos cidadãos, como a integridade física e corporal do indivíduo, cuja concretização demanda a necessidade de efetivar, com a maior abrangência possível, os direitos sociais, com o desenvolvimento de prestações positivas do Estado (SOARES, 2010).

Todos têm intrinsecamente, por força de sua condição humana, esses direitos, além de outros dela decorrentes, pelo que não é possível falar em dignidade quando não se tem os direitos capazes de lhe proporcionar uma vida digna em sociedade (LIBERATI, 2010).

Nesse âmbito, destaca-se o entendimento de Pablo Stolze Gagliano (2013. p. 78), quando aduz que "a dignidade humana somente é preservada na medida em que se garante o respeito à dimensão existencial do indivíduo, não apenas em sua esfera pessoal, mas, principalmente, no âmbito das suas relações sociais".

Nascimento (2009, p. 410), analisa o princípio da dignidade da pessoa humana sob a ótica da violação e possível afronta:

A dignidade é um valor subjacente a numerosas regras de direito. A proibição de toda ofensa à dignidade da pessoa humana é uma questão de respeito ao ser humano, o que leva o direito positivo a protegê-la, a garanti-la e a vedar atos que podem de algum modo levar à sua violação, inclusive na esfera dos direitos sociais.

Nesse contexto oportuno mencionar os entendimentos, pelos quais as tornozeleiras eletrônicas poderiam afetar a dignidade da pessoa humana, causando a estigmatização do apenado.

Dentre as hipóteses de medida protetiva de urgência previstas na Lei 11.340 de 2006, destaca-se a proibição de determinadas condutas ao agressor, como por exemplo a aproximação da vítima, de seus familiares e das testemunhas, sendo fixado um limite mínimo de distância entre estes e o agressor (BRASIL, 2006). 
A previsão busca, nesse aspecto, resguardar a integridade física da vítima, evitando a aproximação do seu agressor, que passa, muitas vezes a perseguir a vítima, seus familiares e testemunhas, em todos os locais frequentados por ela.

A Lei 11.340 de 2006 inovou no tocante a proibição do agressor de frequentar os mesmos lugares que a vítima, cabendo ao juiz fixar um limite mínimo de distância entre o agressor e a vítima, familiares e testemunhas, sob pena do ofensor ver decretada sua prisão preventiva. São exemplos de meios aptos a assegurar o cumprimento da medida e consequentemente a proteção da vítima de violência doméstica (BRASIL, 2006).

O monitoramento eletrônico entra ora em discussão acerca de sua possível aplicabilidade nesse âmbito pois o âmbito no qual está inserido (Código de Processo Penal como medidas que visam assegurar o bom funcionamento do processo) é diverso da finalidade das medidas protetivas de urgência previstas na Lei Maria da Penha. Permitindo-se a aplicabilidade de tal instituto no âmbito da Lei Maria da Penha, permite-se o monitoramento do agressor e o acompanhamento de seus movimentos, garantindo que não seja ultrapassado o perímetro estabelecido pelo juiz, resguardando a integridade da vítima (LIBERATI, 2010).

Especificamente nos casos de violência doméstica, não há previsão legal de utilização da monitoração eletrônica. No rol contemplado das medidas protetivas de urgência não Lei n 11.343/06 não há qualquer previsão nesse sentido, surgindo aí a questão problema que estabelece a reflexão do presente artigo.

Importante mencionar, nesse contexto, o Projeto de Lei $\mathrm{n}^{\circ} 3980$, de 2019 , da autoria da senadora Renilde Bulhões, que busca incluir na Lei $n^{\circ} 11.340$, de 7 de agosto de 2006 a utilização de equipamento de monitoração eletrônica pelo agressor nas garantias de efetividade das medidas protetivas de urgência. Segundo a explicação da emenda, o agressor utilizaria o equipamento de monitoramento eletrônico para garantir a efetividade das medidas protetivas de urgência, e a vítima teria também um dispositivo eletrônico que a alerte sobre o descumprimento das medidas. O projeto encontra-se desde 09/09/2019 com a Comissão de Constituição, Justiça e Cidadania (BRASIL. SENADO FEDERAL, 2020).

Assim, questiona-se acerca da possibilidade da utilização de tal instrumento, tendo em vista que as finalidades das medidas cautelares diversas da prisão são diferentes daquelas que dão a razão de ser das medidas protetivas de urgência: 
enquanto aquelas buscam assegurar o bom andamento do próprio processo, essas visam assegurar a integridade física da vítima. O questionamento se justifica ao considerar que que "ainda há grande dificuldade na compreensão do exato sentido da cautelaridade no processo penal e de sua vinculação estreita com os requisitos da urgência, da necessidade e da indispensabilidade" (ZILLI, 2010, p. 447).

Inobstante a ausência de previsão legal na própria Lei Maria da Penha, a monitoração eletrônica vem sendo considerada pela jurisprudência como mecanismo necessário e adequado no cumprimento de medidas protetivas de urgência, como se pode inferir a partir de algumas decisões recentes, destacando-se recente decisão do Tribunal de Justiça do Paraná, abaixo colacionada:

HABEAS CORPUS. CRIMES DE AMEAÇA (ART. 147 DO CP - FATOS 3 E 6), PERTURBAÇÃO DO SOSSEGO (ART. 65 DO DECRETO-LEI N ${ }^{\circ}$ 3688/1941 - FATOS 1, 3, 5 E 6) E DESCUMPRIMENTO DE MEDIDA PROTETIVA DE URGÊNCIA (ART. 24-A DA LEI No 11.340/2006 LEI MARIA DA PENHA - FATOS 1, 2, 3, 4 E 6)1. ADUZIDO EXCESSO DE PRAZO PARA A FORMAÇÃO DA CULPA. SEGREGAÇÃO PREVENTIVA DECRETADA EFETIVAMENTE PELO DESCUMPRIMENTO DE 1 Denúncia - mov. 10.1 - processo $n^{\circ} 0000578-54.2019 .8 .16 .0105$. Habeas Corpus $n^{\circ}$ 0019911-16.2019.8.16.0000 MEDIDAS PROTETIVAS DE URGÊNCIA NO ÂMBITO DA VIOLÊNCIA DOMÉSTICA. MOTIVAÇ̃̃O IDÔNEA PAUTADA NO PERICULUM LIBERTATIS CONCRETO. TRÂMITE PROCESSUAL RECURSAL QUE DEVE SER ANALISADO SOB O PRISMA DA RAZOABILIDADE E DA PROPORCIONALIDADE, E NÃO PURAMENTE COM BASE NUM CRITÉRIO MATEMÁTICO. NECESSIDADE DA GARANTIA DA ORDEM PÚBLICA E DE ASSEGURAR À VÍTIMA A EFETIVIDADE DAS MEDIDAS PROTETIVAS ANTERIORMENTE DEFERIDAS. OBSERVADO O TRÂMITE NORMAL DO PROCESSO. PRISÃO PROCESSUAL QUE NÃO SE CONFUNDE COM PRISÃO PENA. PENA CORPORAL QUE SOMENTE PODE SER LEVADA EM CONSIDERAÇÃO QUANDO PROFERIDA SENTENÇA CONDENATÓRIA. ROGO DE SUBSTITUIÇÃO POR MEDIDAS CAUTELARES DIVERSAS (ART. 319 DO CPP) E MONITORAMENTO ELETRÔNICO. CONDIÇÕES PESSOAIS FAVORÁVEIS QUE, POR SI SÓS, NÃO REFLETEM NA CONCESSÃO DE LIBERDADE SE PRESENTES OS REQUISITOS DA PRISÃO PREVENTIVA, E, MENOS AINDA CONDUZEM A SUBSTITUIÇÃO DA PRISÃO PREVENTIVA, SE PRESENTES OS REQUISITOS Habeas Corpus $n^{\circ}$ 0019911-16.2019.8.16.0000 AUTORIZADORES DA CUSTÓDIA CAUTELAR. SUBSTITUIÇÃO QUE, AO CASO, NÃO ATENDE AO RESTAURO DA GARANTIA DA ORDEM PÚBLICA. ORDEM DENEGADA. ( ${ }^{\mathrm{a}}$ C. Criminal - 0019911-16.2019.8.16.0000 - Rel.: Desembargador José Maurício Pinto de Almeida - J. 30.05.2019) (PARANÁ, 2019)

O tema vem sendo tratado também em outros Tribunais brasileiros, a exemplo do Tribunal de Justiça de Goiás e de Sergipe: 
HABEAS CORPUS. ARTIGO 1ㅇ, INCISO I, ALÍNEA 'A', DA LEI No 9.455/97, C/C LEI MARIA DA PENHA. AUSÊNCIA NEGATIVA DE AUTORIA. VIA INADEQUADA. NÃO CONHECIMENTO. MONITORAMENTO ELETRÔNICO FACE AO DESCUMPRIMENTO DAS MEDIDAS PROTETIVAS. AUSÊNCIA DE CONSTRANGIMENTO ILEGAL.

1. A tese de negativa de autoria deve ser apreciada em processo de conhecimento e não no rito célere do 'writ', ante a necessidade de exame de mérito e aprofundada valoração probatória.

2. Não há se falar em constrangimento ilegal a fixação de monitoramento eletrônico (art. 319, inciso IX, do CPP) ao paciente que descumpriu as medidas protetivas de urgência, revelando a cautelar necessária para se evitar o descumprimento de outras medidas protetivas outrora impostas. ORDEM PARCIALMENTE CONHECIDA E, NESTA EXTENSÃO DENEGADA. (Processo 11020720188090000. Órgão Julgador 1A CAMARA CRIMINAL. Publicação DJ 2469 de 19/03/2018. Julgamento. 20 de fevereiro de 2018. Relator Des. Itaney Francisco Campos) (GOIÁS, 2018).

HABEAS CORPUS, AMEAÇA, VIOLÊNCIA DOMÉSTICA, DESCUMPRIMENTO DAS MEDIDAS PROTETIVAS DE URGÊNCIA, MONITORAMENTO ELETRÔNICO, SITUAÇÃO ACOBERTADA PELA LEI MARIA DA PENHA, MANUTENÇÃO DA MEDIDA COMO FORMA DE GARANTIR A INTEGRIDADE FÍSICA E PSÍQUICA DA VÍTIMA, CONSTRANGIMENTO ILEGAL NÃO VERIFICADO, MONITORAÇÃO MANTIDA, HABEAS CORPUS DENEGADO - DECISÃO UNÂNIME. (Habeas Corpus Criminal $n^{\circ} 201900303477 n^{\circ}$ único000114123.2019.8.25.0000 - CÂMARA CRIMINAL, Relator (a): Ana Lúcia Freire de A. dos Anjos - Julgado em 12/03/2019) (SERGIPE, 2019).

Observe-se que nas recentes decisões foi afastada a hipótese de constrangimento ilegal, priorizando a eficácia e efetividade - com toda a problemática que esses termos comportam e mereçam um capítulo à parte - da proteção estabelecida na Lei Maria da Penha, por meio do monitoramento eletrônico do agressor.

Para que as medidas protetivas tenham a efetividade esperada - dizendo-se aqui no sentido do estrito cumprimento e observância por parte do agressor -, como por exemplo a de distanciamento mínimo, em metros, depende-se da fiscalização, medida essa - a fiscalização em si - que não possui previsão expressa de maneira pormenorizada na Lei Maria da Penha. É nesse sentido que as determinações judiciais de uso de tornozeleiras eletrônicas possibilitariam ser verificada a obediência à decisão judicial de afastamento e trazer a prometida segurança para a vítima, tendo em vista que dado o caráter de tal instrumento processual, tenderia a se inibir o descumprimento da medida protetiva pelo agressor, uma vez que o dispositivo eletrônico acompanharia de modo mais direto e constante o cumprimento de quais sejam as medidas impostas. 
Nesse sentido, o que se observa é que, no caso de aceite de tal possibilidade, a medida cautelar processual da tornolezeira eletrônica figuraria como medida acessória à medida principal - qualquer daquelas constantes no rol do artigo 22 da Lei n. ${ }^{0} 11.340 / 06$-, uma vez que o intuito seria o de justamente conferir o cumprimento efetivo da medida protetiva decretada, pelo que a medida do monitoramento eletrônico aplicada no âmbito da violência doméstica contra a mulher pode trazer proveitosos resultados (MORAIS, 2014).

Assim, se por um lado a refutação da possibilidade ora em análise pode se estabelecer diante da consideração de se tratar de um rol taxativo as previsões constante no artigo 22 da Lei Maria da Penha, tem-se por outro a defesa da instrumentalização da medida ao considerar que as tornozeleiras eletrônicas acabariam servindo nesse sentido justamente como hipótese de garantia de cumprimento de medida judicial, estando atrelado, portanto, ao asseguramento da regularidade do próprio processo.

\section{CONSIDERAÇÕES FINAIS}

O direito é constantemente influenciado pelos acontecimentos sociais de um país, refletindo na evolução da ciência jurídica e resultando em novas formas de tutela dos direitos da pessoa. Nesse contexto, despontam inúmeras possibilidades e meios para garantir direitos, especialmente quanto aos interesses da mulher, reflexo de uma crescente valoração e reconhecimento da vulnerabilidade da mulher, que são tratados no contexto dos direitos sociais e em harmonia com os princípios norteadores do direito.

A Lei Maria da Penha tem papel fundamental na garantia dos direitos sociais, coexistido como instrumento de efetivação do princípio da dignidade da pessoa humana. As mudanças trazidas pela Lei $n^{\circ} 11.340 / 2006$ se apresenta exatamente neste cenário, pois trata da proteção de um grupo antes menosprezado, mesmo porque "os padrões e valores sexistas e misóginos ainda são ressignificados e interiorizados, inclusive pela própria mulher".

Nesse sentido, questiona-se sobre a possibilidade da utilização de medida cautelar processual para se fazer valer, com mais concretude, as medidas protetivas de urgência. De maneira mais específica: é possível determinar o uso das 
tornozeleiras eletrônicas ao agressor a fim de se manter um maior controle sobre o cumprimento das medidas protetivas de urgência no âmbito da Lei Maria da Penha?

Muito embora ausente previsão legislativa direta acerca da utilização do monitoramento eletrônico como mecanismo para se fazer valer o cumprimento das medidas de proteção previstas na Lei Maria da Penha, verifica-se que pela jurisprudência há certa adesão à utilização do monitoramento eletrônica nesse sentido, inserindo tal medida cautelar processual como instrumento de fiscalização das medidas protetivas de urgência, ampliando assim os mecanismos previstos na Lei Maria da Penha.

Em que pese entendimentos contrários, têm se observado também posicionamentos favoráveis à utilização da monitoração eletrônica, no sentido de que a utilização não configuraria constrangimento ilegal, tampouco violaria o princípio da dignidade humana, sendo mecanismo que permitiria a proteção da vítima sem a necessidade de ser o agressor recolhido ao sistema carcerário - esse já em crise.

Talvez a redação do $\$ 1^{\circ}$ do artigo 22 da Lei n. ${ }^{0} 11.340 / 06$ corrobore para tal entendimento, uma vez que prevê que as medidas protetivas de urgência constantes no rol ali exposto "não impedem a aplicação de outras previstas na legislação em vigor, sempre que a segurança da ofendida ou as circunstâncias o exigirem, devendo a providência ser comunicada ao Ministério Público". Em assim sendo, nos casos de afastamento do lar e de proibição de aproximação ou contato, por exemplo, o uso da monitoração eletrônica acabaria por monitorar a distância em relação à vítima, conferindo maior segurança e observância ao cumprimento da medida.

Deste modo, o monitoramento eletrônico do agressor funcionaria como meio de fiscalizar efetivamente o (des)cumprimento da medida imposta, estabelecendo-se um maior controle sobre as medidas de proteção à vítima no âmbito da Lei Maria da Penha.

\section{REFERÊNCIAS}

ÁVILA, Thiago André Pierobom de. Lei Maria da Penha. Uma análise dos novos instrumentos de proteção às mulheres. Projeto Busca Legis 2007. Disponível em: http://www.egov.ufsc.br/portal/sites/default/files/anexos/13477-13478-1-PB.pdf Acesso em: 10 abr. 2020. 
BIANCHINI, Alice. Lei Maria da Penha: Lei n. 11.340/2006: aspectos assistenciais, protetivos e criminais da violência de gênero. 3. ed. São Paulo: Saraiva, 2016.

BRASIL. Senado Federal. Atividade Legislativa. Disponível em:

https://www25.senado.leg.br/web/atividade/materias/-/materia/137675. Acesso em 20 jun 2020.

BORGES, Izabella. Novas perspectivas da Lei Maria da Penha: violência psicológica como lesão psíquica. Disponível em: https://www.conjur.com.br/2020-jun10/escritos-mulher-violencia-psicologica-lesao-psiquica-saude-mulher. Acesso em: 20 jul. 2020.

FERNANDES, Valéria Diez Scarance. Lei Maria da Penha: o processo penal no caminho da efetividade: abordagem jurídica e multidisciplinar. São Paulo: Atlas, 2015.

FERRAZ, Fernanda Tortato Carneiro; SANTOS, Rafael Carla dos. Lei Maria da Penha e a Lei da Transparência: a fragilidade das medidas protetivas para funcionárias públicas. In: TOMAZONI, Larissa Ribeiro, et al. Mulheres e o direito: um chamado à real visibilidade. 1.ed. Curitiba: Sala de Aula Criminal, 2020.

GOIÁS. Tribunal de Justiça de Goiás. Habeas-corpus n 11020720188090000. Órgão Julgador 1A CAMARA CRIMINAL. Publicação DJ 2469 de 19/03/2018. Julgamento. 20 de fevereiro de 2018. Relator Des. Itaney Francisco Campos. Pesquisa de jurisprudência. Disponível em: https://www.jusbrasil.com.br/processos/220955785/processo-n51390333020198090000-do-tjgo. Acesso em: 10 ago. 2020.

GURGEL, Maria Antonieta Rigueira Leal; FREITAS, Gefferson Dias Nascimento de. Uma ponta para a paz entre o cravo e a rosa: a possibilidade de aplicação da justiça restaurativa aos conflitos domésticos e familiares derivados da condição de gênero. In: FRANCO, Ângela Barbosa; GURGEL, Maria Antonieta Rigueira Leal (Orgs.). Direito e Música: a poética como contributo para a compreensão da justiça. Belo Horizonte: Arraes Editores, 2019.

LIBERATI, Wilson Donizeti. Comentários ao Estatuto da Criança e do Adolescente. 11. Ed. São Paulo: Malheiros, 2010.

LÍDICE, Roberta. Estudos feministas por um direito menos machista. Violência doméstica e a necessidade de enfrentamento através da implementação de políticas públicas. Implicações no cenário atual brasileiro. 3.ed. Florianópolis: Tirant lo blanch, 2018.

LOPES JR., Aury. Prisões cautelares. 4.ed. São Paulo: Saraiva, 2013.

MORAIS, Paulo José lasz de. Tornozeleira eletrônica efetiva Lei Maria da Penha para agressor e vítima. Disponível em: https://www.conjur.com.br/2014-ago-

07/paulo-morais-tornozeleira-eletronica-efetiva-lei-maria-penha. Acesso em: 20 set. 2020. 
NASCIMENTO, Amauri Mascaro. Curso de direito do trabalho. 24. ed. São Paulo: Saraiva, 2009.

PARANÁ. Tribunal de Justiça do Paraná. Habeas-corpus nº 0019911 16.2019.8.16.0000 - Rel.: Desembargador José Maurício Pinto de Almeida - J. 30.05.2019. Pesquisa de jurisprudência. Disponível em: https://www.jusbrasil.com.br/processos/225287969/processo-n-00005785420198160105-do-tjpr. Acesso em: 10 ago. 2020.

SERGIPE. Tribunal de Justiça do Sergipe. Habeas-corpus $n^{\circ} 201900303477 n^{\circ}$ único0001141-23.2019.8.25.0000 - CÂMARA CRIMINAL, Relator (a): Ana Lúcia Freire de A. dos Anjos - Julgado em 12/03/2019. Pesquisa de jurisprudência. Disponível em: https://tj-se.jusbrasil.com.br/jurisprudencia/686348372/habeascorpus-criminal-hc-11412320198250000?ref=serp. Acesso em: 10 ago. 2020.

SOARES, Ricardo Maurício Freire. O Princípio Constitucional da Dignidade Humana: em busca do direito justo. 1.ed. São Paulo: Saraiva, 2010.

SOUZA JUNIOR, Luciano de Oliveira. Direito e tecnologia: uma alternativa ao sistema carcerário nacional. 2008. Disponível em:

http://srv02.fainor.com.br/revista/index.php/memorias/article/viewFile/12/31. Acesso em: 20 jun 2020.

SOUZA, Sérgio Ricardo. Comentários à lei de combate à violência contra a mulher. Curitiba. Jurua, 2007. Disponível em: https://administradores.com.br/ artigos/lei-maria-da-penha-medidas-civeis-medidas-protetivas-mulher-violenciadomestica.

STUKER, Paola. Para além da justiça criminal: violência doméstica, pauperização das mulheres e contingências de programa social. In: JOHAS, Bárbara; AMARAL, Marcela; MARINHO, Rossana. Violências e Resistências: estudos de gênero, raça e sexualidade. Teresina: EDUFPI, 2020.

TAPOROSKI FILHO, Paulo Silas; VOLLET, Silviély. Lei Maria da Penha: breves apontamentos sobre a contextualização de sua inserção no ordenamento jurídico brasileiro. Revista científica eletrônica Academia de Direito, Mafra/SC, v. 1, p. 83-99. 05 de nov/2019.

ZILLI, Marcos Alexandre Coelho. Ainda que tardia, que venha a liberdade: breve panorama sobre a prisão cautelar no direito brasileiro. Revista Brasileira de Ciências Criminais. v. 85, jul./ago. 2010.

Artigo recebido em: 16/10/2020

Artigo aceito em: 11/11/2020

Artigo publicado em: 13/10/2021 